\title{
Microscopic amyloid deposits in the heart valves: a common local complication of chronic damage and scarring
}

\author{
Y GOFFIN
}

From the Department of Pathology, University Hospital Brugmann, Brussels, and the Université Libre de Bruxelles, Brussels, Belgium

SUMMARY The presence of amyloidosis was detected in 33 out of $213(15.5 \%)$ mitral and aortic valves that had been surgically removed for chronic valvular disease. No correlation could be found with age or type of valvular disease, neither was there any clinical evidence of an associated generalised amyloidosis. Histologically, the amyloid deposits were microscopic and restricted to areas of dense scar tissue. No comparable alterations were found in 147 unaltered valves which served as controls. The term 'dystrophic' is proposed to describe this particular form of valvular amyloidosis.

The deposition of amyloid in the heart valves is a well-known occurrence in generalised primary amyloidosis and in senile cardiac amyloidosis. A survey of the literature concerning cardiac localisations of amyloidosis shows that valvular involvement is a relatively infrequent finding (Silwer and Lindblom, 1926; Lubarsch, 1929; Koller, 1932; Israel, 1933; Kerwin, 1936; Koletsky and Stecher, 1939; Dillon and Evans, 1942; Lindsay and Knorp, 1945; Lindsay, 1946; Ranström, 1946; Dahlin, 1949; Dahlin and Edwards, 1949; Ballinger, 1949; Hulbert and Meyer, 1949; Jones and Frazier, 1950; Woolf, 1950; Symmers, 1956a/b; Benson and Smith, 1956; Frederiksen et al., 1962; Pomerance, 1966; Buja et al., 1970). This may explain why, although amyloidosis of the heart muscle was already known by 1857 (Virchow, 1857), valvular amyloidosis had to wait until 1922 to be reported in a case of what now appears to have been the senile form of cardiac amyloidosis (Kann, 1922).

The structures mainly affected by cardiac amyloidosis are the blood vessels and the myocardium, particularly in the interauricular septum and in the ventricular wall (Pomerance, 1966; Buja, et al., 1970). Where valvular deposits are present, they may be found in one or more valves, the mitral and tricuspid being the most frequently involved. Other noteworthy features of this classical type of valvular amyloidosis are that the deposits occur in previously unaltered valves and that in senile cases they apparently develop as a consequence of an age-related degenerative disorder of the connective tissue.

Received for publication 28 June 1979
The purpose of the present paper is to report another type of valvular amyloidosis which appears in relation to local scarring. It was discovered accidentally by histological examination of chronically diseased heart valves which had been surgically removed for valvular stenosis and/or incompetence. Subsequently we extended our investigation in order to include adequate controls which were taken from necropsy material.

\section{Material and methods}

A total of 226 surgically removed heart valves were examined. The final diagnoses, based on the histological lesions and the clinical data were: healed process of chronic or recurrent rheumatic disease, subacute or healed bacterial endocarditis, congenital malformation, sclerotic age-related degeneration. and mucoid degeneration. In 56 cases the exact nature of the valvulopathy could not be determined (Table 1).

Controls consisted of a total of 147 heart valves removed at necropsy from patients who had died from various causes, valvulopathies being excluded. The valves were fixed in $4 \%$ formaldehyde or, when calcified, in a solution containing $4 \%$ formaldehyde and $7.5 \%$ nitric acid. Paraffin sections 5 to $8 \mu \mathrm{m}$ thick were stained with haematoxylin-erythrosinsaffron, elastin-van Gieson, alkaline Congo red, and thioflavin T. Material that was Congo red positive and showed green dichroism under polarised light was identified as amyloid. The size and distribution of the amyloid deposits were estimated on thio- 


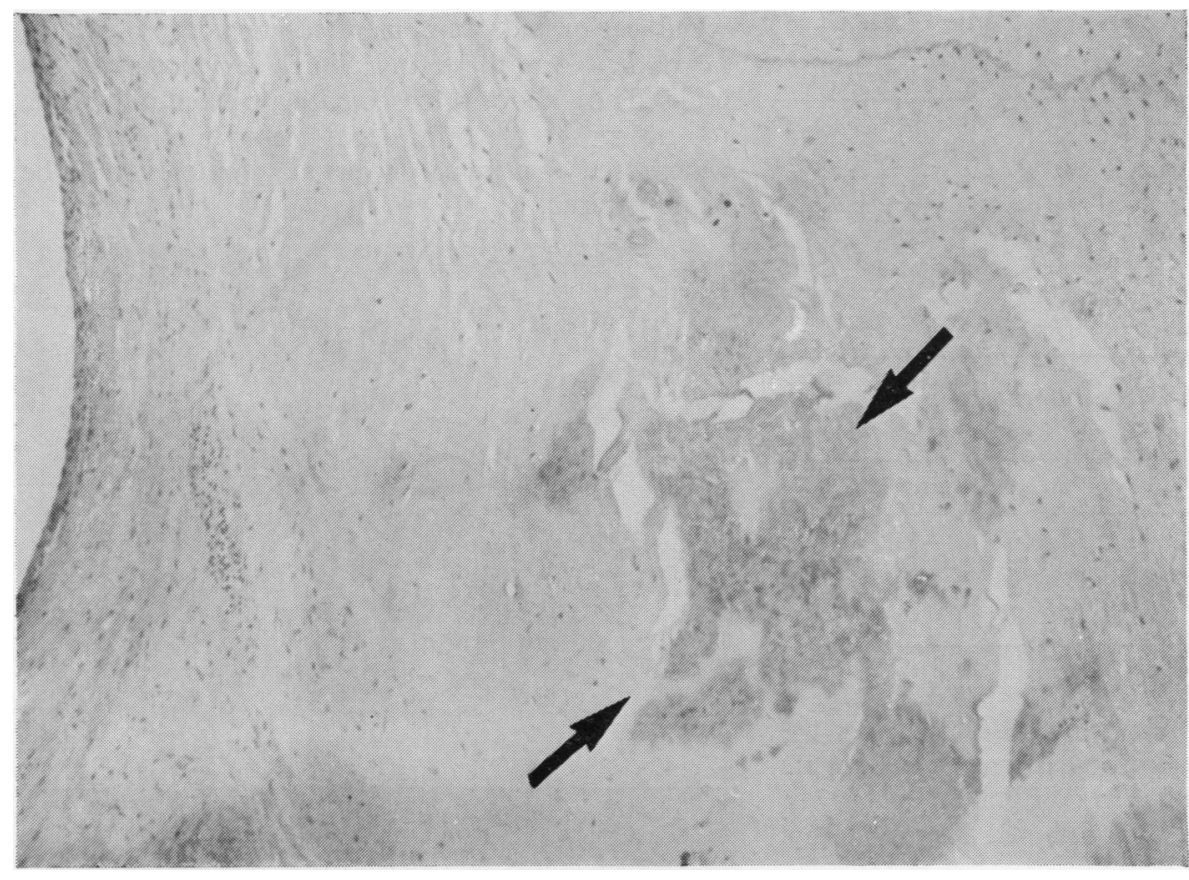

Fig. 1 Sclerotic thickening of mitral valve in a 63-yearold woman without any anamnestic, clinical, or histological evidence of endocarditis:

multiple minute foci of amyloid (between the two arrows) in an area of heavy and poorly cellular collagen deposition. (Congo red $\times 20$ )

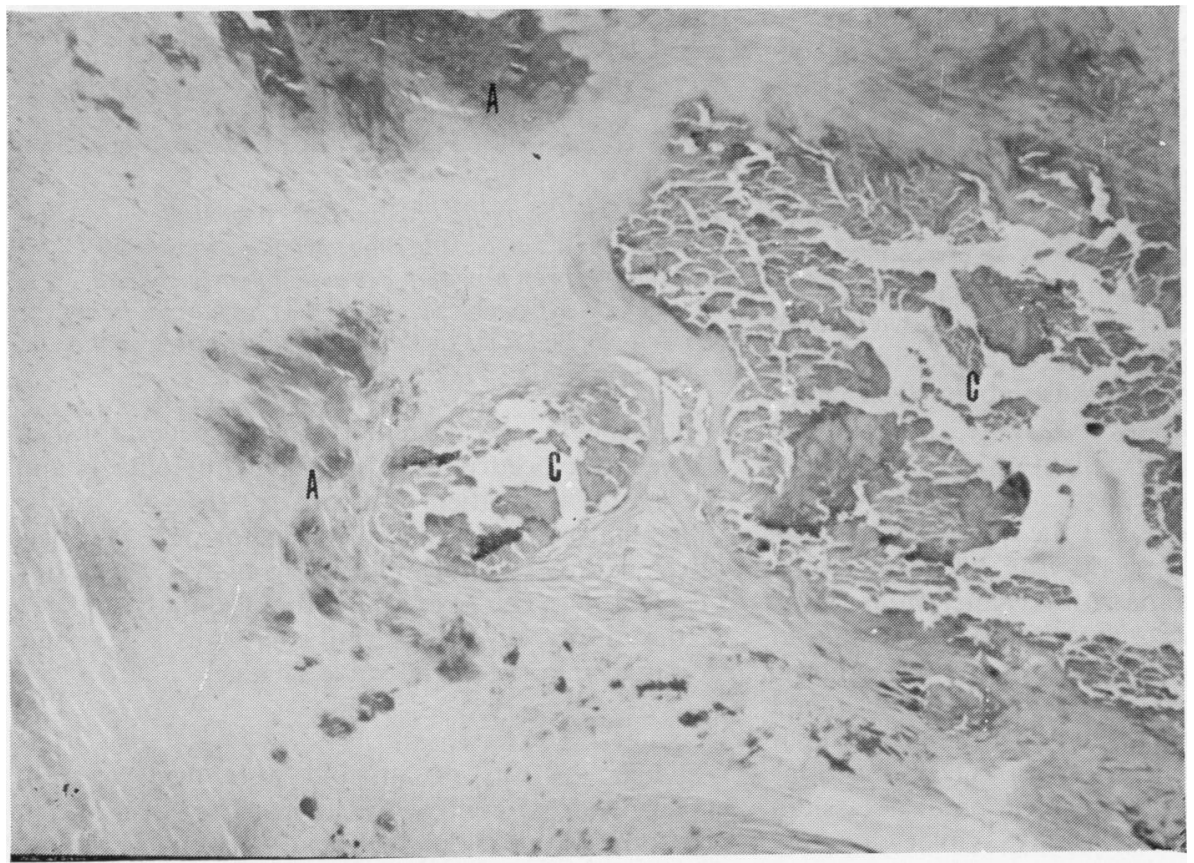

Fig. 2 Sclerotic and calcified scar of aortic valve in a 31-year-old man with chronic rheumatic disease: Microscopic amyloid foci in poorly cellular scar tissue $(A)$ in the neighbourhood of calcific deposits $(C)$ (Congo red $\times 10$ ). 
Table 1

(A) Heart valve amyloidosis in 226 surgical specimens

\begin{tabular}{llcc}
\hline Nature of valvulopathy & $\begin{array}{l}\text { Total no. of } \\
\text { cases }\end{array}$ & Vo. positive & Percentage \\
\hline Chronic inflammatory & 94 & 18 & $19 \cdot 1$ \\
$\begin{array}{l}\text { Sclerotic, degenerative or } \\
\quad \text { malformative }\end{array}$ & 55 & 11 & $20 \cdot 0$ \\
Mucoid degenerative & 21 & 0 & $0 \cdot 0$ \\
Sclerotic, unknown origin & 56 & 4 & 7.0 \\
All origins & 226 & 33 & 15.5 \\
\hline
\end{tabular}

(B) Heart valve amyloidosis in 147 control postmortem specimens

\begin{tabular}{|c|c|c|}
\hline Type of amyloidosis & No. of cases & Percentage \\
\hline $\begin{array}{l}\text { Senile cardiac amyloidosis } \\
\text { Generalised secondary } \\
\text { amyloidosis }\end{array}$ & 1 & \\
\hline All types & 2 & $1 \cdot 4$ \\
\hline
\end{tabular}

* Only chordae tendineae affected.

flavine-T preparations. In some selected cases the sections were treated with potassium permanganate before Congo red staining (Wright et al., 1977). Some sections were also stained with methyl violet.

\section{Results}

SURGICAL SPECIMENS

Amyloid was identified in 15 out of $107(14 \%)$ mitral valves and in 18 out of $106(17 \%)$ aortic valves. The deposits were not apparent to naked-eye examination and were discovered only by histological examination, which disclosed the presence, within the substance of the valves, of minute foci of histochemically typical amyloid. They were mainly located in densely sclerotic and poorly vascularised scar tissue (Fig. 1), frequently in close proximity to calcific deposits (Fig. 2). They were sometimes present in ares of eosinophilic, apparently degenerated, fibrous tissue. They never showed any relation to blood vessels or foci of connective tissue cell proliferation. They were also absent from areas of mucoid degeneration or loose fibrosis, an observation that may explain why they never occurred in the 13 specimens of tricuspid valves. They were seldom present in the chordae tendineae or old synechiae. In one 50-year-old man with a history of chronic rheumatic fever, amyloid deposits were found in an atherosclerotic plaque situated at the base of the mitral valve. The amyloid deposits consistently fluoresced with thioflavin $T$ and exhibited a green dichroism under polarised light after Congo red staining (Fig. 3). These reactions were unaffected by prior decalcification or potassium permanganate treatment. Methyl violet staining, when performed, demonstrated metachromasia. In no patient was there any clinical evidence of generalised amyloidosis. Three patients eventually came to necropsy in our department: no signs of generalised or primary cardiac amyloidosis could be demonstrated.

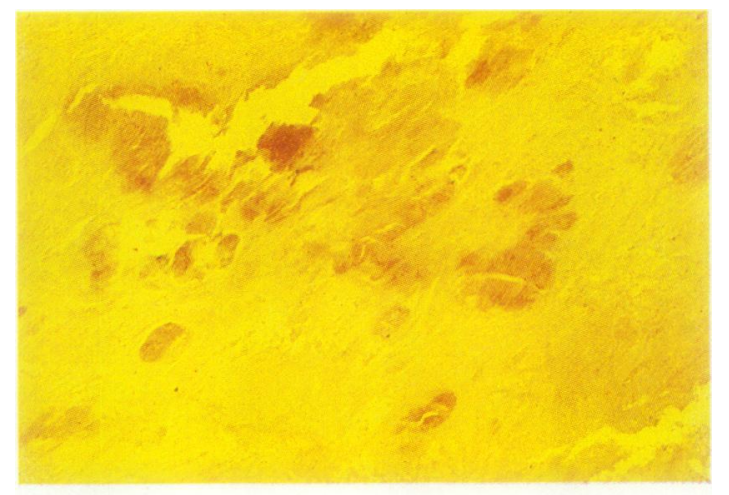

Fig. 3(A)

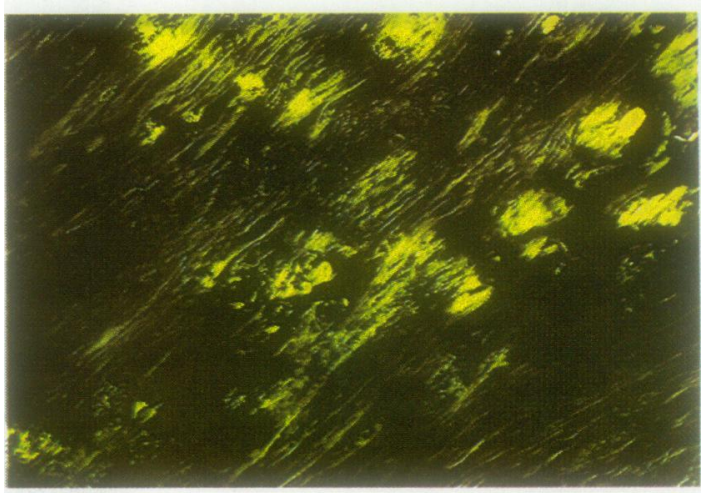

Fig. 3(B)

Fig. 3 Calcific aortic disease with congenital bicuspidy in a 52-year-old man. Minute deposits of amyloid are present within dense and poorly cellular fibrous tissue (Congo red $\times 40)$ : $(A)$ by normal light; (B) by polarised light to show the characteristic apple green dichroism.

Statistically, no correlation could be established between the occurrence of valvular amyloidosis and the age of the patient (chi square) (Fig. 4), or the inflammatory, versus malformative or pure degenerative nature of the underlying valve pathology (Table $1 \mathrm{~A}$ ). The sexes were about equally affected in the mitral valve series, but there was a 2:1 male dominance in the aortic valve series.

\section{CONTROL SPECIMENS}

Valvular deposits of amyloid were discovered in only one of 147 control specimens. They occurred in the form of multiple superficial verrucous nodules 

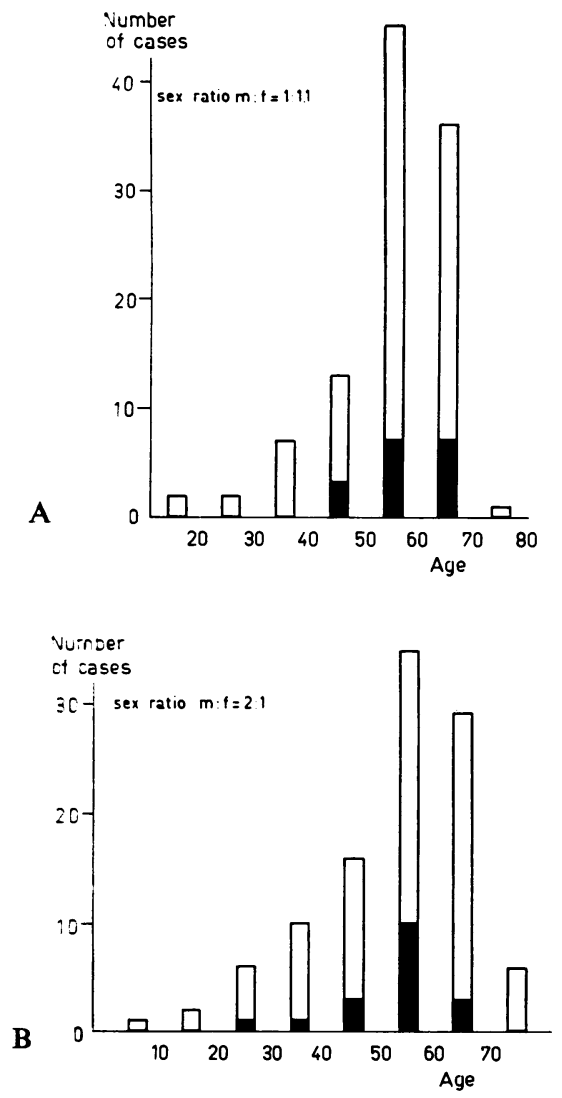

Fig. 4 Total numbers of surgical specimens and numbers of amyloid positive specimens per decade respectively at the mitral $(A)$ and aortic sites $(B)$, with reference to sex distribution: $\square$ no. of cases examined; cases with amyloid deposits.

in a 66-year-old man who had a severe grade of senile cardiac amyloidosis.

The control group included one case of generalised secondary amyloidosis affecting a 53-year-old man: the heart was spared except for small deposits in the chordae tendineae of the mitral valve (Table $1 \mathrm{~B}$ ).

\section{Discussion}

Our investigations have brought to light the hitherto unsuspected existence of a distinctive type of heart amyloidosis. It was detected in 33 out of $213(15.5 \%)$ mitral and aortic valves which had been surgically removed for chronic valvular heart disease. It was encountered with comparable frequency in young and older patients, none of whom showed any clinical evidence of generalised amyloidosis. Histologically, the amyloid deposits were characteristi- cally small and restricted to the site of densely sclerotic or sclerocalcific lesions. Tricuspid valves, which never showed such extensive damage as did the mitral and aortic valves, were at the same time consistently spared from amyloidosis. The deposits occurred in indiscriminate association with inflammatory, degenerative, and malformed alterations of the valve. The lack of correlation with any specific type of valvular disease strongly suggests that the condition is a local complication of progressive destruction and scarring of the valvular connective tissue. According to Schwartz (1976), amyloid deposits may develop from scar hyalin and from fibrin. This form of valvular amyloidosis appears to be a good example of such a transformation. By comparison with the analogous situation existing in respect to pathological calcification we propose to designate this particular form of valvular amyloidosis dystrophic.

By contrast, when 147 heart valves removed at necropsy from patients who had no overt valvular disease were examined histologically, amyloidosis was discovered in only one case, that of a 66-year-old man with typical senile amyloidosis of the heart. In this instance, however, the deposits were quite dissimilar from those observed in the surgical specimens. They were so extensive as to be apparent to naked-eye examination; they furthermore produced verrucous elevations which correspond to their superficial localisation in the valve tissues. The findings in our control group accord with the general experience (Kann, 1922; Silwer and Lindblom, 1926; Lubarsch, 1929; Koller, 1932; Israel, 1933; Kerwin, 1936; Koletsky and Stecher, 1939; Dillon and Evans, 1942; Lindsay and Knorp, 1945; Lindsay, 1946; Ranström, 1946; Dahlin 1949; Ballinger, 1949; Hulbert and Meyer, 1949; Jones and Frazier, 1950; Woolf, 1950; Symmers 1956b; Benson and Smith, 1956): previously unaltered valves are not frequently the seat of amyloid, and when they are involved, as may happen in generalised amyloidosis or in localised senile heart amyloidosis, the deposits are quite unlike those seen in severe damaged valves.

Dystrophic amyloidosis of the heart valves thus appears as a unique type of alteration. It has hitherto seemingly escaped recognition, presumably because of the smallness of the deposits and their easy confusion with foci of hyalinised connective tissue. The well-known difficulty of identifying amyloid with certainty must also be taken into account. We used as a criterion the green dichroism imparted by Congo red under polarised light, a reaction that is generally accepted as the most reliable and sensitive test for amyloid. In addition, in one case, which is not included in this series, 


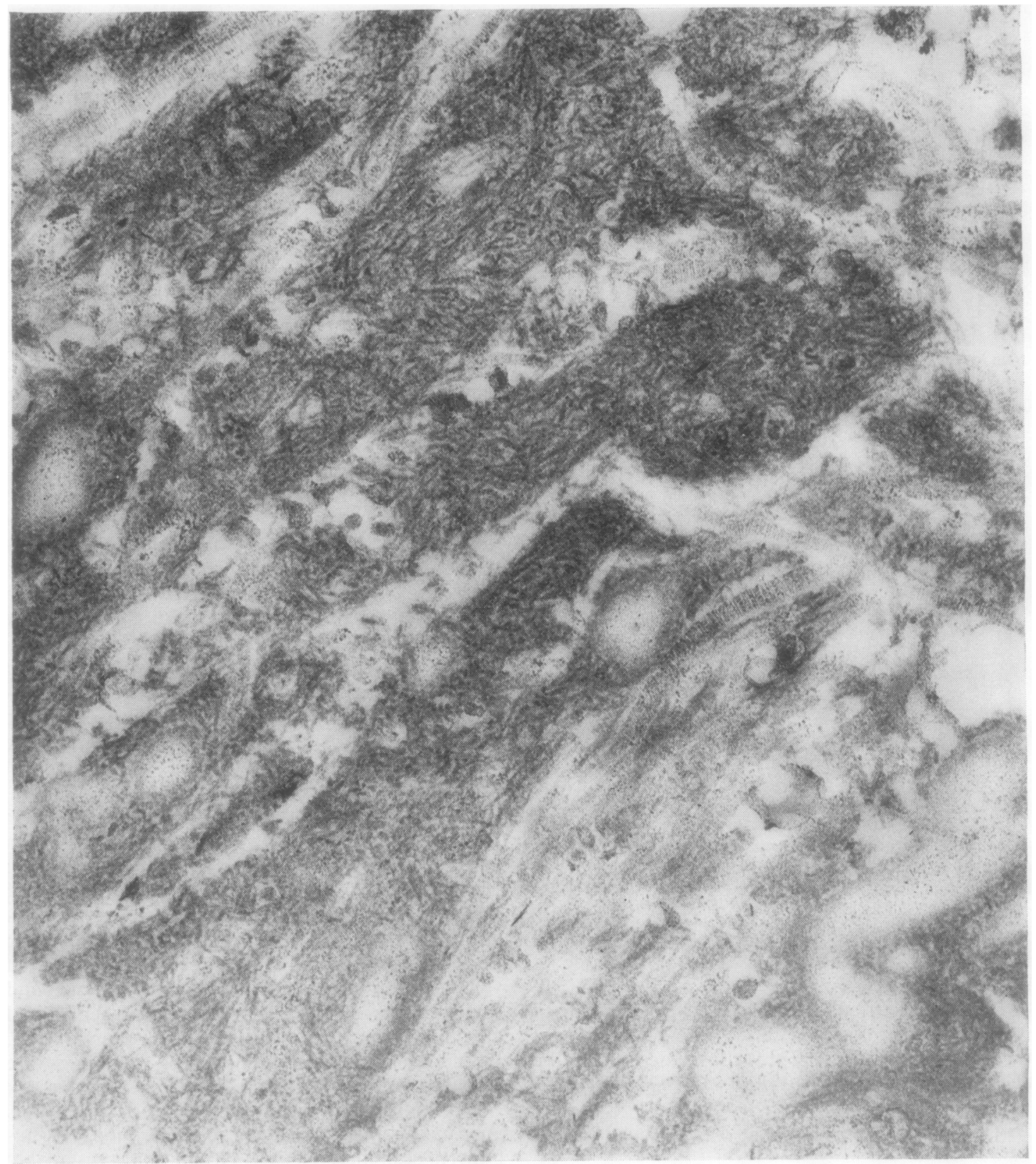

Fig. 5 Electron micrograph of a bicuspid aortic valve. Small areas of microfibrillary substance are disseminated in a matrix composed of collagenous fibres ant elastic me:nbranes. The microfibrils are short, haphazardly stacked up, and have a mean diameter of $9 \cdot 5 \mathrm{~nm}(\times 540 \%)$.

electron microscopy was performed on the heavily calcified bicuspid aortic valve of a 54-year-old individual. Examination of iodine and Congo red positive areas confirmed the presence of micro- fibrils with ultrastructural features specific for amyloid (Shirahama and Cohen, 1967) (Fig. 5).

The characteristic green dichroism under polarised light was unaffected by prior treatment with 
potassium permanganate. According to Wright et al. (1977), this method allows an easy distinction between different chemical types of amyloid. Secondary amyloid, with protein AA as its major component, is the only one to be permanganatesensitive. The amyloids of immunoglobulin or endocrine origin are permanganate-resistant. The same is true for the senile type of cardiac amyloid, in which Westermark et al. (1977) have recently established the presence of a specific protein subunit. A point that deserves further consideration is whether dystrophic amyloidosis could affect structures other than the heart valves. The question arises for atheromatous lesions, whether situated at the base of the heart valve as was observed in one of our surgical specimens or in the aortae as was described by Wright et al. (1969). These authors were, however, unable to demonstrate any significant relationship between the presence of amyloid and the degree of atherosclerosis.

With regard to the pathogenesis of this condition, one can only speculate as to the respective roles of three possible factors: $(a)$ the presence in the circulating plasma of amyloid precursors; $(b)$ an increased permeability of the damaged valvular surface; and (c) the local appearance, within the altered ground substance of the valvular connective tissue, of abnormal substances with a strong capacity to bind the amyloid precursors, which have premeated this tissue.

Sincere thanks are offered to Professor P Potvliege, who made the electron microscopic observation, to Professor W Hijmans for helpful criticism, to Mr V Van Cleerhout for skilful technical assistance, and to Mrs S Pieters for typing the manuscript.

\section{References}

Ballinger, J. (1949). Amyloid heart disease. American Journal of Medical Sciences, 217, 308-313.

Benson, R., and Smith, J. F. (1956). Cardiac amyloidosis. British Heart Journal, 18, 529-543.

Buja, L. M., Khol, N. B., and Roberts, W. C. (1970). Clinically significant cardiac amyloidosis. Clinicopathologic findings in 15 patients. American Journal of Cardiology, 26, 394-405.

Dahlin, D. C. (1949). Primary amyloidosis, with report of 6 cases. American Journal of Pathology, 25, 105-119.

Dahlin, D. C., and Edwards, J. E. (1949). Amyloid localized in the heart. Proceedings of the Staff meetings of the Mayo Clinics 24, 89-98.

Dillon, J. A., and Evans, L. R. (1942). Primary amyloidosis. A report of 3 cases. Annals of Internal Medicine, 17, 722-731.

Frederiksen, T., Gøtzsche, H., Harboe, N., Kiaer, W., and Mellemgaard, K. (1962). Familial primary amyloidosis with severe amyloid heart disease. American Journal of Medicine, 33, 328-348.

Hulbert, B., and Meyer, H. (1949). Primary amyloidosis of the heart. American Heart Journal, 38, 604-609,

Israel, I. (1933). Ein Fall von lokalem Amyloid. Thesis, Tübingen. H. Poppinghaus, Bochum-Langendreer. Cited by Koletsky, S., and Stecher, R. M. (1939). Archives of Pathology, 27, 267-288.

Jones, R. S., and Frazier, D. B. (1950). Primary cardiovascular amyloidosis. Its clinical manifestations, pathology and histogenesis. Archives of Pathology, 50, 366-384.

Kann, G. (1922). Ein Fall von isolierter Amyloidose des Herzens. Virchows Archiv für Pathologische Anatomie und Physiologie, 237, 22-31.

Kerwin, A. J. (1936). Idiopathic amyloid disease of the heart. Journal of Laboratory and Clinical Medicine, 22, 255-261.

Koletsky, S., and Stecher, R. M. (1939). Primary systemic amyloidosis. Involvement of cardiac valves, joints and bones, with pathologic fracture of the femur. Archives of Pathology, 27, 267-288.

Koller, F. (1932). Über atypische Amyloidose als Ursache von Herzinsuffizienz. Schweizerische medizinische Wochenschrift, 62, 522-525.

Lindsay, S. (1946). The heart in primary systemic amyloidosis. American Heart Journal, 32, 419-437.

Lindsay, S., and Knorp, W. F. (1945). Primary systemic amyloidosis. Archives of Pathology, 39, 315-322.

Lubarsch, O. (1929). Zur Kenntnis ungewöhnlicher Amyloidablagerungen. Virchows Archiv für Pathologische Anatomie und Physiologie, 271, 867-889.

Pomerance, A. (1966). The pathology of senile cardiac amyloidosis. Journal of Pathology and Bacteriology, 91, 357-367.

Ranström, S. (1946). Amyloidosis myocardii. Acta Medica Scandinavica, 123, 111-125.

Schwartz, P. (1976). Über Amyloidose als Manifestation und Ursache der präsenilen und senilen Degeneration. Fortschritte der Medizin, 15, 890-898.

Shirahama, T., and Cohen, A. S. (1967). High-resolution electron microscopic analysis of the amyloid fibril. Journal of Cell Biology, 33, 679-708.

Silwer, H., and Lindblom, A. F. (1926). Ein Fall von allgemeiner Amyloidose ohne nachweisbare Ursache. Acta Medica Scandinavica, 64, 529-545.

Symmers, W. St. C. (1956a). Primary amyloidosis: a review. Journal of Clinical Pathology, 9, 187-211.

Symmers, W. St. C. (1956b). Amyloidosis: five cases of primary generalized amyloidosis and some other unusual cases. Journal of Clinical Pathology, 9, 212-228.

Virchow, R. (1857). Neue Beobachtungen über amyloide Degeneration. Archiv für pathologische Anatomie und Physiologie, 11, 188-189.

Westermark, P., Natvig, J. B., and Johansson, B. (1977). Characterization of an amyloid fibril protein from senile cardiac amyloid. Journal of Experimental Medicine, 146, 631-636.

Woolf, C. R. (1950). Primary systemic amyloidosis with gross cardiac involvement. South African Medical Journal, 24, 146-150. 
Wright, J. R., Calkins, E., Breen, W. J., Stolte, G., and Schultz, R. T. (1969). Relationship of amyloid to aging. Medicine (Baltimore), 48, 39-60.

Wright, J. R., Calkins, E., and Humphrey, R. L. (1977). Potassium permanganate reaction in amyloidosis. Laboratory Investigation, 36, 274-281.
Requests for reprints to: Dr Y Goffin, Hopital Universitaire Brugmann, van Gehuchten plein 4, 1020 Brussels, Belgium. 